\title{
Acoustic-orthographic interface in L2 phonology by L1 Cypriot-Greek speakers
}

\author{
Sviatlana Karpava ${ }^{1}$, Elena Kkese ${ }^{2}$ \\ ${ }^{1}$ Department of English Studies, University of Cyprus \\ 2Department of Education and Linguistics, UCLan, Cyprus \\ https://doi.org/10.36505/ExLing-2020/11/0026/000441
}

\begin{abstract}
The present study investigated the acoustic-orthographic interface in the phonology of L2 English by L1 Cypriot-Greek (CG) speakers. Seventy L1 CG undergraduate students completed a written dictation task, which examined how contrastive English vowels and consonants on word-level are perceived by CG and how the use of L2 affects these perceptions based on the different phoneme inventories and orthographies of CG and English. The findings suggest that there is an effect of L1 CG phonological and orthographic systems on L2 English vowel and consonant sound perception and written production.
\end{abstract}

Keywords: L2 phonology, perception, vowels, consonants, acoustic-orthographic interface

\section{Effects of orthography on explicit phonemic processing}

Orthographic forms or spellings are usually ignored in the L2 (second language) classroom context since the skill of spelling is believed to develop on its own (Kkese, 2020a). Nonetheless, L2 teachers have long known that orthographic forms can affect pronunciation since language learners are simultaneously exposed to the orthographic and phonological forms of the L2. Orthographic forms representing the sounds and/or words of a language in writing can affect language learners but also perception, production, and acquisition of L2 phonology and morphology.

With reference to the influence of orthography on L2 phonology, this can be positive facilitating L2 acquisition and pronunciation (Escudero et al., 2008); it can be negative leading to non-nativelike pronunciation (Bassetti, Atkinson, 2015; Young-Scholten, Langer, 2015); it can have mixed or no effects (Escudero, 2015). This happens because L2 learners have already acquired the phonological system and orthographic properties of the L1 (first language) and may draw on this knowledge while acquiring the target language (Kkese, 2020b).

L2 learners of English with L1 Standard Modern Greek (SMG) and/or Cypriot Greek (CG) background can have inappropriate inference from the orthography based on the wrong assumption that L2 English orthography is phonemic and there is a grapheme-phoneme correspondence (GPC) as in the

ExLing 2020: Proceedings of $11^{\text {th }}$ International Conference of Experimental Linguistics, 12-14 October 2020, Athens, Greece 
orthography of the L1 in which there is constant reading of graphemes (Kkese, 2020a).

The aim of this study is to investigate the acoustic-orthographic interface in L2 phonology by examining speech perception and written production of L2 English vowels and consonants by L1 CG users. As a result, for this study, the following research question will be investigated:

RQ1: Is there difference between perception and production of vowel and consonant phonemes in L2 English by L1 CG students? What is the effect of word frequency, the number of syllables in a word, the position of a sound in a word and the characteristics of acoustic input (male vs female voice)?

\section{Methodology}

Seventy CG undergraduate university students (1 1 st year), who were learners of L2 English at a private, English-speaking university, participated in the study. There were 40 male and 30 female participants with normal speech and hearing. Their age ranged from 17 to 27 (Mean 19.8) and their L2 English proficiency was from low intermediate to advanced (5-9 IELTS scores, Mean 6.5).

In this study, a word dictation task was implemented to test L2 English vowel and consonant perception and production of sounds by L1 CG students, their word recognition skills, and accuracy of decoding acoustic speech signal into words. The dictation task had 120 test items: 60 for vowels and 60 for consonants. There were 10 conditions for consonant sounds (6 test items each): $[ð],[\mathrm{z}],[\theta],[\mathrm{v}],[\mathrm{d}],[\mathrm{r}],[\mathrm{h}],[\mathrm{b}],[\mathrm{g}],[\mathrm{I}]$ and 10 conditions for vowel sounds $(6$

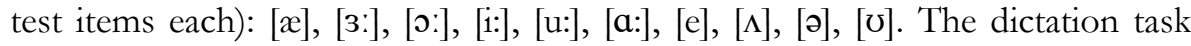
was split into 6 dictation sessions; 20 test items for each (10 consonant and 10 vowel test items).

\section{Results and Discussion}

Overall, the results suggest that the dictation task seems to be quite difficult for students due to differences between the L1 CG and L2 English phonological and orthographical systems. There was a high percentage of no production and substitution errors. The participants had more non-target word transcription results for both vowels and consonants. This could also be due to a very strict scoring system: only accurate word recognition and word transcription was measured as target-like performance, see Table 1 .

According to the paired samples t-test, there is a statistically significant difference between target and non-target production, for both consonants and vowels $(t(69)=-9.958, p=.000)$; vowel target and non-target production $(t(69)=$ 8.398, $p=.000)$; consonant target and non-target production $(t(69)=-11.271$, $p=.000)$; and between target production of consonants and vowels $(t(69)=$ 6.492, $p=.000$ ). 
Table 1. Vowel vs. consonant perception and production.

\begin{tabular}{|c|c|c|c|c|c|c|}
\hline Overall & \multicolumn{3}{|c|}{ Vowels } & \multicolumn{3}{|c|}{ Consonants } \\
\hline target & \multicolumn{3}{|c|}{$48.67 \%$} & \multicolumn{3}{|c|}{$49.81 \%$} \\
\hline non-target & \multicolumn{3}{|c|}{$51.33 \%$} & \multicolumn{3}{|c|}{$50.19 \%$} \\
\hline Frequency & \multicolumn{2}{|c|}{ high } & Low & high & \multicolumn{2}{|c|}{ low } \\
\hline target & \multicolumn{2}{|c|}{$55.82 \%$} & $41.51 \%$ & $59.29 \%$ & \multicolumn{2}{|c|}{$40 \%$} \\
\hline non-target & \multicolumn{2}{|c|}{$44.18 \%$} & $58.49 \%$ & $40.70 \%$ & \multicolumn{2}{|c|}{$60 \%$} \\
\hline Position & initial & middle & Final & initial & middle & final \\
\hline target & $59.42 \%$ & $44.51 \%$ & $40 \%$ & $54.31 \%$ & $48 \%$ & $45 \%$ \\
\hline non-target & $40.58 \%$ & $55.50 \%$ & $60 \%$ & $45.69 \%$ & $52 \%$ & $55 \%$ \\
\hline Syllables & \multicolumn{2}{|c|}{ one } & two & one & \multicolumn{2}{|c|}{ two } \\
\hline target & \multicolumn{2}{|c|}{$47.85 \%$} & $46.89 \%$ & $44.75 \%$ & \multicolumn{2}{|c|}{$52.90 \%$} \\
\hline non-target & \multicolumn{2}{|c|}{$52.15 \%$} & $53.11 \%$ & $55.25 \%$ & \multicolumn{2}{|c|}{$47.10 \%$} \\
\hline Voice & \multicolumn{2}{|c|}{ Male } & Female & male & \multicolumn{2}{|c|}{ female } \\
\hline target & \multicolumn{2}{|c|}{$45.16 \%$} & $49.45 \%$ & $50.46 \%$ & \multicolumn{2}{|c|}{$49 \%$} \\
\hline non-target & \multicolumn{2}{|c|}{$54.84 \%$} & $50.56 \%$ & $49.54 \%$ & \multicolumn{2}{|c|}{$51 \%$} \\
\hline
\end{tabular}

Taking each condition separately into consideration, the participants had more target-like performance with respect to the following consonant sounds: [h] (85.18\%), [x] (70.20\%), [z] (59.38\%), [d] (54.44\%) and [b] (56.74\%) while the

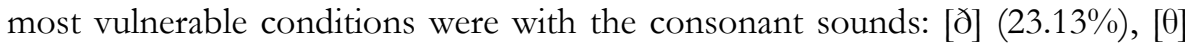
(37\%), [v] (42.91\%), [r] (29\%) and [g] (40.07\%).

These findings are in agreement with Kkese, Karpava (2019), though the experimental tasks were different. The participants had mainly substitution and no production errors regarding consonant conditions. The substitution errors were based on the similarity or contrast of voice feature and manner of articulation. There is a strong effect of word frequency on target perception and production of consonant sounds as high-frequency words elicit more target-like answers. Overall, high-frequency words have an advantage over low-frequency words in terms of the number of acoustic cues accumulated over time.

The students were better in terms of comprehension and production of the following vowel sounds: [ə] (schwa) (74.62\%), [u:] (64.19\%), [ə:] (53.81\%) and [e] $(52.86 \%)$ than the rest of the vowel sounds: [æ] (44.17\%), [i:] (47.68\%), [a:]

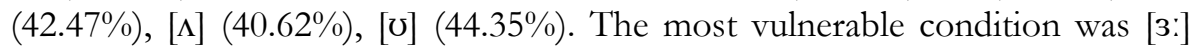
$(21.90 \%)$. The high production of the schwa sound [ə] can be explained by the fact that it is the most common vowel sound in English, which can be spelled with any vowel grapheme. It appears on unstressed syllables and has a neutral mouth position.

This can be due to the differences between English and CG phonological and writing systems; in CG, there is no long-short vowel distinction while the 
schwa sound is absent. Non-target perception and production of vowels was characterised by no production and substitution errors based on the similarity of $[\underline{\mathrm{b} b a c k}],[\underline{\mathrm{t}}$ round $]$ and duration features. There was a clear effect of the word frequency on vowel perception and production as high-frequency words triggered more target-like test performance. Other factors, such as number of syllables in a word, position of the sound in a word, and acoustic input characteristics do not influence the written transcription of L2 English words.

Both consonant and vowel data of this study support the idea of Bassetti, Atkinson (2015) and Young-Scholten and Langer (2015) about the negative inter-orthographic effects on L2 phonological representations and L2 sound perception and production.

\section{References}

Bassetti, B., Atkinson, N. 2015. Effects of orthographic forms on pronunciation in experienced instructed second language learners. Applied Psycholinguistics 36, 6791.

Escudero, P. 2015. Orthography plays a limited role when learning the phonological forms of new words: The case of Spanish and English learners of novel Dutch words. Applied Psycholinguistics 36, 7-22.

Escudero, P., Hayes-Harb, R., Mitterer, H. 2008. Novel second-language words and asymmetric lexical access. Journal of Phonetics 36, 345-360.

Kkese, E. 2020a. L2 writing Assessment: The Neglected Skill of Spelling. Newcastle upon Tyne, Cambridge Scholars Publishing.

Kkese, E. 2020b. Phonological awareness and literacy in L2: Sensitivity to phonological awareness and phoneme-grapheme correspondences in L2 English. In Neokleous, G., Krulatz, A., Farrelly, R. (eds.) 2020, Handbook of Research on Cultivating Literacy in Diverse and Multilingual Classrooms. Hershey, PA, USA, IGI Global Press.

Kkese, E., Karpava, K. 2019. Applying the Native Language Magnet Theory to an L2 setting: Insights into the Cypriot Greek adult perception of L2 English. In E. Babatsouli, E. (ed.), Proc. of the International Symposium on Monolingual and Bilingual Speech 2019, 67-74, Chania, Greece.

Young-Scholten, M., Langer, M. 2015. The role of orthographic input in second language German: Evidence from naturalistic adult learners' production. Applied Psycholinguistics 36, 93-114. 